\title{
TWO NEW SPECIES OF THE DROSOPHILA SERIDO SIBLING SET (DIPTERA, DROSOPHILIDAE)
}

\author{
Rosana Tidon-Sklorz ${ }^{1}$ \\ Fábio M. Sene ${ }^{2}$
}

\begin{abstract}
Drosophila antonietae sp. nov. and D. gouveai sp. nov. are members of the D. buzzatii cluster of the $D$. repleta species group of the genus Drosophila. They can be distinguished from their cryptic species, D. borborema Vilela \& Sene, 1977, D. koepferae Fontdevila \& Wasserman, 1988,D. serido Vilela \& Sene, 1977, and D. seriema Tidon-Sklorz \& Sene, 1995 by morphological, genetic and ecological criteria.
\end{abstract}

KEYWORDS. Drosophila, buzzatii cluster, serido sibling set, Taxonomy, Neotropical.

\section{INTRODUCTION}

The serido sibling set is part of the buzzatii cluster (buzzatii complex) of the genus Drosophila. The buzzatii complex consists of several cactus breeding species inhabiting South and Central America and sharing chromosomal similarities (RuIz et al., 1982; Ruiz \& WasSERMAN, 1993). Drosophila serido was described in 1977 by VILELA $\&$ SENE, and in the following years populations of this species from several regions were studied by means of several genetic markers. These studies suggest that $D$. serido is a polytypic species based on the male genitalia morphology (SILVA \& Sene, 1991), presence of paracentric inversions in the polytene chromosomes (Tosi \& SENE, 1989), metaphase chromosome morphology (BAIMAI et al., 1983), esterase isozyme pattern (LAPENTA et al., 1995, 1998) and degree of reproductive isolation (MADI-RAVAZZI et al., 1997). However, until recently the distribution pattern of these genetic markers was not fully understood (SENE et al., 1982, 1988).

A comprehensive sampling program carried out in several locations in South America, has enabled a more detailed characterization of each member of these closely related species. In 1988, SENE et al. argued that the distribution of D. serido in South America is particularly interesting because some populations differ from others in several

1. Departamento de Genética e Morfologia, Instituto de Ciências Biológicas, Universidade de Brasília, C.P. 04457, CEP 70919-970 Brasília, DF, Brasil. (rotidon@unb.br)

2. Departamento de Genética, Faculdade de Medicina de Ribeirão Preto, Universidade de São Paulo, Av. Bandeirantes 3900 , CEP 14049-900 Ribeirão Preto, SP, Brasil. (famesene@usp.br) 
characters. This is the case for the Argentinean and Bolivian populations, raised to species level as Drosophila koepferae by FontDEvila et al. (1988), and for those living in the "Cadeia do Espinhaço" in Brazil. The latter were described by TIDON-SKLORZ \& SENE (1995a) as Drosophila seriema.

At present, four species are included in the Drosophila serido sibling set: $D$. koepferae (Argentina and Bolivia), D. borborema VIlela \& SEne, 1977 and D. seriema (both from northeastern Brazil), and the group of populations currently known as $D$. serido (in various areas of open vegetation in South America: VILELA et al., 1983; Tidon-Sklorz et al., 1994; Tidon-SKLORZ \& SEne, 1995b).

We describe Drosophila antonietae (previously classified as $D$. serido type D by Silva \& Sene, 1991 and references thereafter) and Drosophila gouveai (previously classified as D.serido type B by SILVA \& SENE, 1991 and references thereafter), in terms of morphological, genetic and ecological differences.

\section{Drosophila (Drosophila) antonietae sp. nov.}

(Figs. 2,7)

External characters of imagines. Arista with 4 dorsal and 3 ventral branches; antennae yellowish with bases dark brown; front light brown, pollinose. Anterior, middle orbital, and posterior vertical arising from a yellowish area. Hairs of anterior orbits, posterior orbital, anterior vertical, and postvertical with basal dark spots. Middle orbital about half the length of other two. Second oral about half the length of first. Carina broad below, sulcated. Palpi pale yellow, with several bristles. Face yellowish brown. Cheeks yellowish gray, their greatest width about 1/4 greatest diameter of eye. Eyes vermilion slightly lighter than those of D. gouveai, with short black pile. Acrostichal hairs in 8 rows; no prescutellars; anterior scutellars convergent. Sterno-index about 0.8 . Mesonotum gray, pollinose, bristles arising from dark spots with tendency to fuse. Scutellum gray with fused brown spots, pleurae brown. Halteres pale yellow. Legs uniformly light brown. Apical bristles on first and second tibiae, preapicals on all three. Abdomen pale yellow, each segment with strongly contrasting, interrupted, wide, dark brown band, this bending to anterior margin at angle of tergite, leaving a small irregular pale area. Wings clear, veins brown, apex of first costal section black. Costal index about 2.6; 4th vein index about $1.8 ; 5 \mathrm{X}$ index about $1.2 ; 4 \mathrm{C}$ index about 0.9 . Two welldeveloped bristles at apex of first costal section; third costal section with heavy bristles on its basal 1/3. Length of body 2.2-3.1 mm (in living specimens); wings about $2.5 \mathrm{~mm}$.

Internal characters of imagines and terminalia. Testes orange, with about 3 inner and 2 outer coils. Epandrium with 7-16 bristles, usually 10. Cerci not fused. Surstylus with 9-13 primary teeth, usually 10 . Aedeagus as in fig. 2.

Chromosomes. The basic metaphase plate of the Drosophila buzzatii cluster consists of four pairs of telocentric autosomes, one pair of small dot 6th chromosomes and one pair of sex chromosomes ( $\mathrm{X}$ telocentric and $\mathrm{Y}$ acrocentric). Compared to the basic type, D. antonietae has a slightly larger 6th chromosome pair, the long arms of $\mathrm{X}$ and $\mathrm{Y}$ chromosomes are longer, and the whole $\mathrm{X}$ chromosome is more heterocromatic (BAIMAI et al., 1983). The chromosomal arrangements are: fixed chromosomal inversions Xabc; $2 \mathrm{abmnx} \mathrm{z}^{7}$; $3 \mathrm{~b}$; polymorphic inversions: $2 \mathrm{y}^{8}, 2 \mathrm{z}^{8}$ and $5 \mathrm{e}$ (described by Tosi \& SENE, 1989 , as "2e", "2d" and 5a, respectively). 


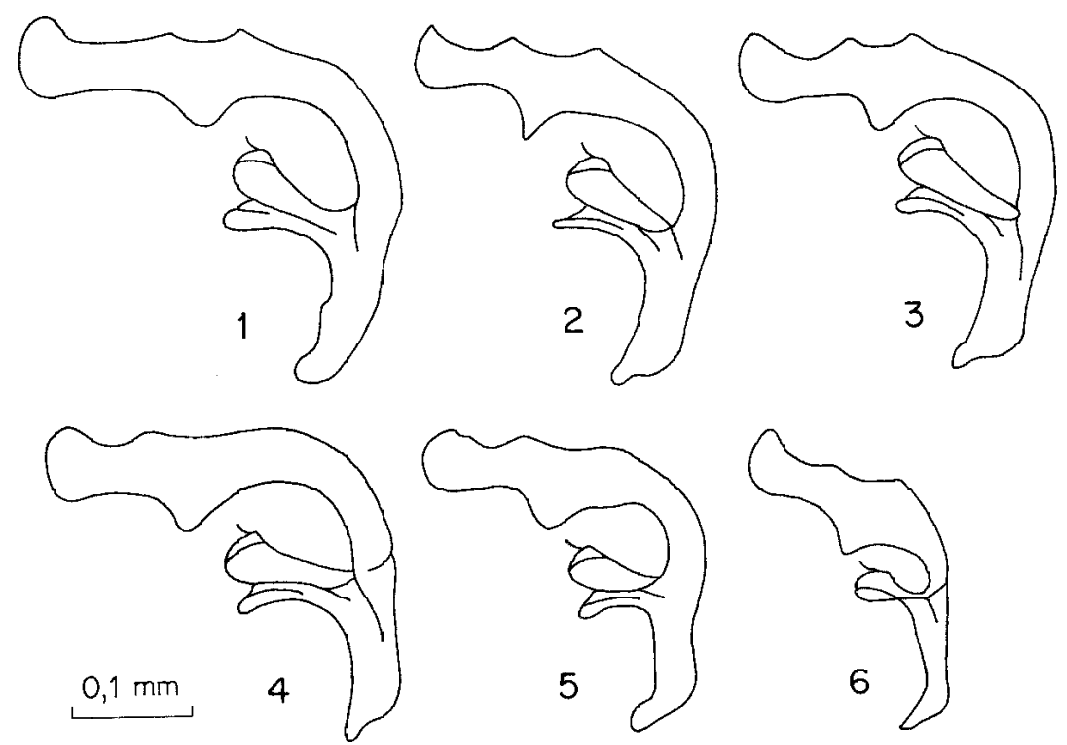

Figs. 1-6. Rigth lateral view aedeagal apodemes and parameres of the the Drosophila serido sibling set species. 1, D. koepferae Fontdevila \& Wasserman, 1988 (isofemale line $\mathrm{B}_{25} \mathrm{D}_{7}$ from La Rioja, Argentina); 2, D. antonietae sp. nov. (paratype, Serrana, São Paulo); 3, D. gouveai sp. nov. (paratype, Analândia, São Paulo); 4, D. serido Vilela \& Sene, 1977 (isofemale line $\mathrm{B}_{53} \mathrm{Q}_{5}$ from Milagres, Bahia); 5, D. seriema (isofemale line $\mathrm{B}_{95} \mathrm{C}_{3}$ from Serra do Cipó, Minas Gerais); 6, D. borborema Vilela \& Sene, 1977 (isofemale line $\mathrm{D}_{54} \mathrm{~B}_{5}$, from Grão Mogol, Minas Gerais).

Other Features. Eggs with 4 filaments. Puparia brownish, each anterior spiracle with ca. 14 branches, horn index ca. 2.2.

Type Material. BRAZIL. São Paulo: Serra do Japi, $\sigma^{2}$ holotype, 23-30.III.1994, Sene et al. col.; 20 paratypes: $4 \sigma^{\circ}, 4$, same data as holotype; Serrana, $2 \sigma^{\prime}, 29,18-22$.VIII.1997, Brito et al. col. Paraná: Sengés, $2 \sigma^{\circ}, 29,10-$ 18.V.1995, Sene et al. col. Rio Grande do Sul: Guaritas, 2 ', 2 Y, 10-18.V.1995, Sene et al. col. All in the Museu de Zoologia, Universidade de São Paulo (MZSP), São Paulo, Brazil.

Distribution. Drosophila antonietae is apparently limited to the Paraná river basin in southeastern South America (fig. 7) (with the exception of populations inhabiting the coast of the State of Rio Grande do Sul). We collected this species at the following sites: Brazil, Mato Grosso do Sul: Serra da Bodoquena; São Paulo: Sertãozinho, Serrana, Santa Maria da Serra, Campinas, Serra do Japi, Cabreúva, Itu, S. Paulo; Paraná: Rio Ligeiro, Sengés; Rio Grande do Sul: Jaguari, S. Francisco Assis, Tramandai, Guaritas. Argentina, Resistencia and Puerto Tirol (Chaco).

Etymology. Named in honor of the late drosophilist Maria Antonieta Milani de Moraes.

Diagnosis. Drosophila antonietae can be distinguished from the other species of the $D$. serido sibling set by the shape of the aedeagus (figs. 1-6), although the external morphology of these species is very similar. The metaphase plate, described above, is considered also an autapomorphic character state of this species.

Classification. Drosophila antonietae belongs to the D. buzzatii cluster of the $D$. buzzatii complex (D. mulleri subgroup) of the D. repleta species group. 
Biology. Data on the breeding and feeding niches indicate that this species lives primarily on columnar cacti. We found this species in decayed portions of cacti Cereus hildmaniannus Schumman, 1890 and Opuntia monacantha Haworth, 1819.

\section{Drosophila (Drosophila) gouveai sp. nov.}

(Figs. 3, 7)

The first part of the following description only lists the differences between $D$. antonietae and D. gouveai.

External characters of imagines. Antennae yellowish with brown spots. Eyes vermilion, slightly darker than those of $D$. antonietae with short black pile. Scutellum dark brown, pleurae dark brown. Legs uniformly dark brown. Costal index about 2.7. Length of body $2.4-3.0 \mathrm{~mm}$ (in living specimens); wings about $2.4 \mathrm{~mm}$.

Internal characters of imagines and terminalia. Testes orange, with 2.5 inner and 2.5 outer coils. Epandrium with 4-13 bristles, usually 8. Cerci not fused. Surstylus with 6-14 primary teeth, usually 8 . Aedeagus as in fig. 3 .

Chromosomes. The metaphase plate consists of four pairs of telocentric autosomes, one pair of small dot 6th chromosomes and one pair of sex chromosomes ( $\mathrm{X}$ telocentric and $\mathrm{Y}$ acrocentric). This karyotype probably represents the ancestral configuration of the repleta group (BAIMAI et al., 1983). Fixed chromosomal inversions: Xabc; 2abmnz $\mathrm{e}^{8}$. Polymorphic inversions: "2a" (Tosi \& Sene, 1989).

Other Features. Eggs with 4 filaments. Puparia brownish, each anterior spiracle with ca. 14 branches, horn index ca. 2.2.

Type Material. BRAZIL. São Paulo: Altinópolis, on holotype, 8-12.VIII.1996, Sene et al. col.; 18 paratypes: $3 \sigma^{-1}, 3$, same data as holotype; Analândia, 3 ', 39, 12-16.XII.1994, Sene et al. col. Minas Gerais: Furnas, $3 \sigma^{\circ}, 39$, 04-08.X.1994, Sene et al. col. All in MZSP.

Distribution. Drosophila gouveai was collected in Central region of South America (fig. 7), at the following sites: Brazil, Pernambuco: Petrolina; Bahia: XiqueXique, Santo Inácio, Barreiras, Ibotirama, Cariranha; Goiás: Cristalina; Minas Gerais: Furnas; Mato Grosso do Sul: Miranda, Bela Vista; São Paulo: Altinópolis, Analândia (Brazil). Paraguay: Bella Vista.

Etymology. Named in honor of the drosophilist Antonio Fernando Gouvêa da Silva.

Diagnosis. Drosophila gouveai can be distinguished from the other species of the $D$. serido sibling set by the shape of aedeagus (figs. 1-6), although the external morphologies of these species are very similar.

Classification. Drosophila gouveai belongs to the D. buzzatii cluster of the $D$. buzzatii complex (D. mulleri subgroup) of the D. repleta species group.

Biology. Drosophila gouveai is found in vegetation of rock outcrops: granite inselbergs and sandstone table mountains. Data on the breeding and feeding niches indicate that this species lives, primarily, on columnar cacti. We have found specimens in decayed portions of cacti Pilosocereus machrisii Dawson, 1960 in Altinópolis, São Paulo, and Opuntia ficus-indica Miller, 1788 in Bela Vista, Mato Grosso do Sul (PEREIRA et al., 1983).

Reproductive isolation. Although individuals identified as Drosophila gouveai produce offspring when crossed (without mate choice) with closely related species (MADIRAVAZZI et al., 1997), the resulting hybrids generally have low fertility or are sterile. 


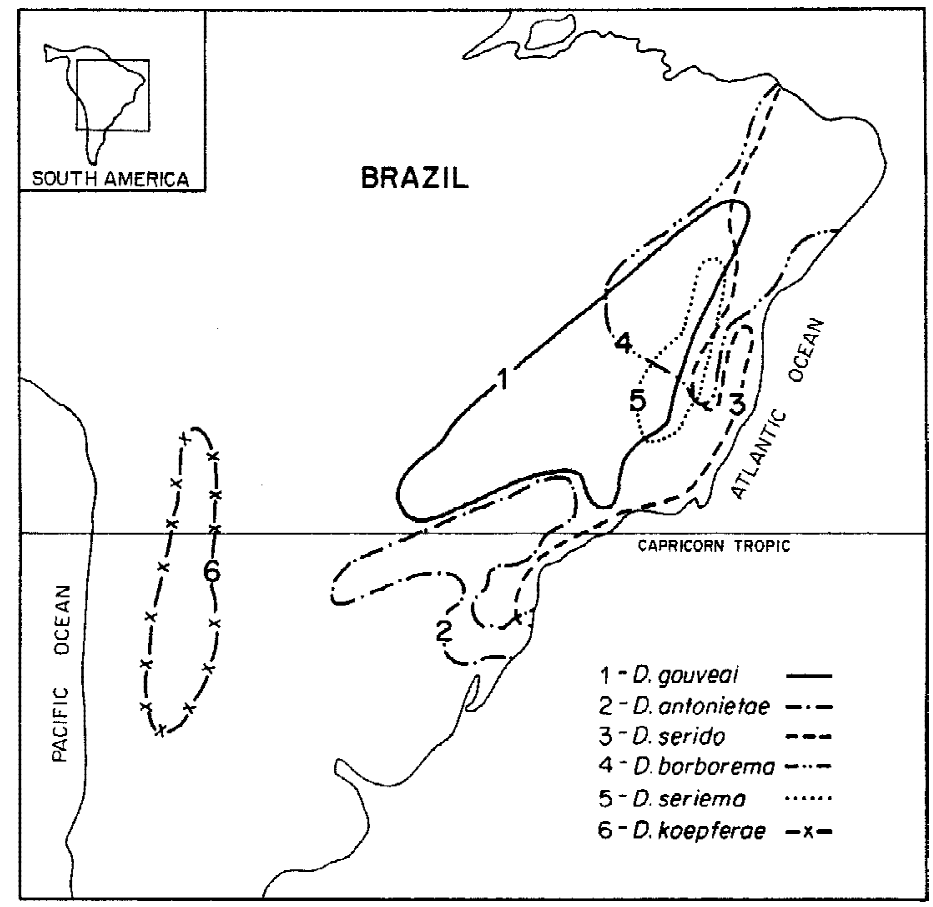

Fig. 7. South America distribution of the known Drosophila serido sibling set.

\section{DISCUSSION}

Several studies of populations of the buzzatii cluster using different markers have shown very clearly that $D$. serido corresponds to a polytypic species. A phylogenetic analysis of characters obtained with these markers, however, demonstrated that the taxon D. serido corresponds to a non-monophyletic entity (Tidon-SKLORZ \& SENE, 1995c). The description of $D$. koepferae and D. seriema on the one hand, and D. antonietae and $D$. gouveai on the other, removed from this sibling set of species differentiated monophyletic groups of populations that deserve specific status.

It is interesting to emphasize that species of this set are morphologically very similar to each other: females are undistinguishable and males can only be identified by their terminalia. However, these species show genetic differences (such as fixed and polymorphic chromosomal inversions), ecological preferences (host plants) and therefore belong to distinct phylogenetic lineages. Drosophila antonietae shares the $2 \mathrm{x}^{7}$ inversion with $D$. serido (stricto sensu), the latter occurring in the northeastern and eastern coast of South America and having a different metaphase plate and terminalia from the former. Drosophila gouveai shares the $2 \mathrm{e}^{8}$ fixed inversion with $D$. seriema and $D$. borborema. These three species, nevertheless, differ with respect to morphology of male terminalia, polymorphic chromosomal inversions and, in addition, are reproductively isolated. The morphological resemblance among the species of this sibling set is probably due to a 
recent common phylogenetic origin, coupled with an apparent absence of selective pressure that led to morphological differentiation (since these species are cactophilic and live in similar environments). This suggests the occurrence of stabile coadapted genic complexes, responsible for the external phenotype.

Acknowledgments. To E. S. Pilla and G. R. Colli (UnB) for critically reading the manuscript, and S.G.Monteiro, M.H.Manfrin, E.M.Moraes, A.M.Cansian, G.C.S.Kuhn, A.Ruiz and P.R.Epifânio, for participating in the collections and for the practical help in different stages of the work. To Marcos R. de Souza for preparing the map. This work was supported by FAPESP, CNPq, FINEP, CAPES, USP and UnB.

\section{REFERENCES}

Baimai, V.; Sene, F.M. \& Pereira, M.A.Q.R. 1983. Heterochromatin and karyotypic differentiation of some neotropical cactus-breeding species of the Drosophila repleta species group. Genetica, Cambridge, 60:81-92.

Fontdevila, A.; Pla, C. et al. 1988. Drosophila koepferae: A new member of the Drosophila serido (Diptera: Drosophilidae) superspecies taxon. Ann. ent. Soc. Am., Maryland, 81:380-385.

Lapenta, A.S.; Bicudo, H.E.M.C. et al. 1995. Esterase patterns of species in the Drosophila buzzatii cluster. Cytobios, Cambridge, 84:13-29.

LAPENTA, A.S.; B ICUDO, H.E.M.C. \& CERON, C.R. 1998. Esterase patterns and phylogenetic relationships of species and strais included in the Drosophila buzzatii cluster. Cytobios, Cambridge, 96:95-107.

Madi-Ravazzi, L.; Bicudo, H.E.M.C. \& Manzato, J.A. 1997. Reproductive compatibility and chromosome pairing in the Drosophila buzzatii complex. Cytobios, Cambridge, 89:21-30.

Pereira, M.A.Q.R.; VIlela, C.R. \& Sene, F.M. 1983. Notes on breeding and feeding sites of some species of the repleta group of the Genus Drosophila (Diptera, Drosophilidae). Ciênc. Cult., São Paulo, 35:1313-1319.

Ruiz, A.; Fontdevila, A. \& Wasserman, M. 1982. The evolutionary history of Drosophila buzzatii. III Cytogenetic relationships between the sibling species of the buzzatii cluster. Genetics, Austin, 101:503-508.

Ruiz, A. \& Wasserman, M. 1993. Evolutionary cytogenetics of the Drosophila buzzatii species complex. Heredity, Edinburgh, 70:582-596.

Sene, F.M.; Pereira, M.A.Q.R. \& VILELA, C.R. 1982. Evolutionary aspects of cactus breeding Drosophila species in South America. In: BARKER, J.S.F. \& S TARMER, W.T. eds. Ecological Genetics and Evolution: the cactusyeast Drosophila model system. Sydney, Academic. p. 97-106.

1988. Contrasting patterns of differentiation inferred from traditional genetic markers in the process of speciation. Pacif. Sci., Honolulu, 42:81-88.

Silva, A.F.G. \& Sene, F.M. 1991. Morphological geographic variability in Drosophila serido (Diptera, Drosophilidae). Revta bras. Ent., São Paulo, 35:455-468.

Tidon-Sklorz, R.; Vilela, C.R. et al. 1994. The genus Drosophila in the Serra do Cipó, state of Minas Gerais, Brazil. Revta bras. Ent., São Paulo, 38 (3/4):627-637.

Tidon-Sklorz, R. \& Sene, F.M. 1995a. Drosophila seriema: A new member of the Drosophila serido (Diptera, Drosophilidae) superspecies taxon. Ann. ent. Soc. Am., Maryland, 88:139-142.

. 1995b. Fauna of Drosophila (Diptera, Drosophilidae) in the northern area of the "Cadeia do Espinhaço", states of Minas Gerais and Bahia, Brazil: biogeographical and ecological aspects. Iheringia, Sér. Zool., Porto Alegre, (78):85-94.

1995c. Evolution of the buzzatii cluster (Drosophila repleta species group) in middle South America. Evolución Biológica, Bogotá, 9:71-85.

Tosi, D. \& Sene, F.M. 1989. Further studies on chromosomal variability in Drosophila serido (Diptera, Drosophilidae). Revta bras. Genet., Ribeirão Preto, 12:729-746.

Vilela, C.R. \& Sene, F.M. 1977. Two new neotropical species of the repleta group of the Genus Drosophila (Diptera, Drosophilidae). Revta bras. Ent., São Paulo, 30:295-299.

Vilela, C.R.; Pereira, M.A.Q.R. \& Sene, F.M. 1983. Preliminary data on the geographical distribution of Drosophila species within morphoclimatic domains of Brazil. II. The repleta group. Ciênc. Cult., São Paulo, 35:66-70.

Recebido em 23.04.2000; aceito em 11.09.2000. 